\title{
The impact of online micro-influencers on behavioural intentions: The case of mobile phone customers in Ho Chi Minh City
}

\author{
Kieu Anh Tai ${ }^{1 *}$, Le Minh Duy ${ }^{1}$, Nguyen The Khai ${ }^{1}$ \\ ${ }^{1}$ Ho Chi Minh City Open University, Vietnam \\ *Corresponding author: tai.ka@ou.edu.vn
}

\begin{abstract}
ARTICLE INFO
ABSTRACT

DOI: $10.46223 / \mathrm{HCMCOUJS.}$

econ.en.11.2.1309.2021

Received: November $12^{\text {th }}, 2020$

Revised: January $23^{\text {rd }}, 2021$

Accepted: January $26^{\text {th }}, 2021$

Keywords:

behavioural intentions; microinfluencers; online opinion leaders; parasocial

interactions; smartphone

The advances of the Internet and social media offer customers nowadays more opportunities to inform their decisions with product information - not only that promoted by the company but also content shared by micro-influencers. This study aims to investigate the impact of online micro-influencers on the customer's behavioural intentions. A survey was conducted using convenience sampling with customers in Ho Chi Minh City who have bought or intended to buy smartphones upon viewing online product reviews. Data, upon having been collected and screened, included 371 usable responses and were analysed using PLS-SEM. Results show that the customer's perceptions of opinion leadership of micro-influencers and their parasocial interactions with microinfluencers positively influence the customer's behavioural intentions (intention to follow the advice and intention to recommend) through message quality. Managerial implications are also discussed in the paper.
\end{abstract}

\section{Introduction}

In traditional marketing communications, information sources could be either the businesses called advertisers disseminating messages about their products or services to the customers or famous individuals called celebrities or Key Opinion Leaders (KOL), who are able to influence the public's opinions and behaviour due to their expertise or attractiveness appeal (Stokburger-Sauer \& Hoyer, 2009). Indeed, much research has been done on the latter type of information source, focusing on celebrities as influencers or opinion leaders. Those studies investigated either the influence of celebrities' personal traits, the congruence of their image that brands want to leverage on secondary brand associations (Gentina, Butori, \& Heath, 2014; Min, Chang, Jai, \& Ziegler, 2019); or the impact of celebrities' endorsement thanks to their image or reputation or the customer's engagement with the celebrity on the consumer's attitude and buying behaviour (Ilicic \& Webster, 2014).

With the advances of the Internet and social network sites, consumers are increasingly given the opportunity to access more information channels and sources of information to evaluate alternatives and make purchase decisions. On online forums and social network sites (social media), there has emerged a number of individuals, through their social media accounts to create, contribute and share useful content for another Internet/ social media users, gradually forming a community of people that "follow", interact and take into account their opinions. Those individuals, commonly known in practice as bloggers and vloggers, are also referred to as 
micro-influencers who influence others' opinions in the internet environment. This type of social influencers, though having fewer followers than traditional celebrities, has more positive followers' interactions (e.g., viewing or re-sharing), thereby generating higher communication effectiveness and efficiency (Abidin, 2016).

Businesses and brands are increasingly interested in finding ways to leverage online "brand ambassadors" who are social media (e.g., YouTube or Facebook) bloggers presenting and reviewing products or services that they tried out and promoted the product to other online users (Sokolova \& Kefi, 2020). The information generated and spread by those social influencers is usually in the form of an image or a short video clip embedded with a product message or textual description. The popularity of the blogger/vlogger phenomenon and User-Generated Content (UGC) have led to the rise of a new form of marketing: "influencer marketing," in which brands or businesses collaborate with online opinion leaders to promote their products or services (De Veirman, Cauberghe, \& Hudders, 2017).

Some research has focused on User-Generated Content (UGC), also called ConsumerGenerated Content (CGC), in terms of Electronic Word-Of-Mouth (EWOM) (Chatterjee, 2011; Trusov, Bucklin, \& Pauwels, 2009). However, some researchers noticed the ephemeral nature of attention and inequal popularity of UGC (Susarla, Oh, \& Tan, 2016). Recently, some researchers have paid attention to online opinion leaders, who could be either celebrities on social network platforms (Li, Lee, \& Lien, 2012) or just individuals who have a lot of followers, share or interact (e.g., tweet or retweet) on online social platforms (De Veirman et al., 2017; Park \& Kaye, 2017).

Researchers suggested that online opinion leaders on online social platforms are necessarily not traditional celebrities (famous athletes or actors); and that the sharing content is not advertising, and even that the quality of image or video content may not be professional. So, it is needed to the persuasive cues about those online opinion leaders (Sokolova \& Kefi, 2020). Prior research revealed that online opinion leaders were often seen as a reliable source of information, having a more positive impact on brand trust and purchase intent than the influence of conventional celebrities (Bijen, 2017; Djafarova \& Trofimenko, 2019). Research also found that online opinion leaders, compared to traditional celebrities, were more likable because of more frequent interactions and more likeliness of the promoting content to be positively rated by consumers (Sokolova \& Kefi, 2020). Nonetheless, there has been scant research on the specific cues of persuasion concerning online opinion leaders on the online social platforms, such as the consumer's perception of their parasocial interactions with online opinion leaders (Sokolova \& Kefi, 2020) or about the extent of the customer's perceptions about an individual who can influence others' opinion online (Casaló, Flavián, \& Ibáñez-Sánchez, 2020).

This study aims to investigate the influence of the specific persuasive cues of online opinion leaders (parasocial interaction and online opinion leadership) on the consumer's perceived message quality, which in turn affects the consumer's behavioural intentions both relating to consumer behaviour (intention to follow the advice of online opinion leaders) and online opinion leader (intention to recommend the online opinion leaders to others). This research is theoretically significant as it contributes to bridging the above-described gap in the literature. In addition, this research also responds to the call for research in emerging market contexts like Vietnam, where marketing research is still limited with mixed evidence (Sheth, 2011), let alone research into online opinion leaders and their cues of persuasion in marketing communications. Furthermore, a report published by the research agency Indochina Research has shown Vietnam has high Internet and social media penetration, with $66 \%$ and $64 \%$ of the population, respectively (Depouilly, 2019). That report also found $88 \%$ of their survey 
respondents indicated product information search as one of their digital activities, implying the context of online product reviews is of practical relevance and significance. Another synthetic statistic by We Are Social and Hootsuite (2019) also indicated a high penetration of smartphones, with also $96 \%$ of internet users accessing via mobile devices.

\section{Theoretical foundation and hypothesis development}

\subsection{Elaboration Likelihood Method (ELM) model}

In communication studies, researchers often draw on ELM theory to explain how receivers (consumers) process information or cues exposed to them (Sokolova \& Kefi, 2020). According to the ELM model, there are two routes of information processing: The central route in which the receivers carefully and thoughtfully process the received information; and the peripheral route in which receivers rely on cues used by the communicator (such as the attractiveness of the information source), rather than to evaluate the merits of information or argument quality (Petty \& Cacioppo, 1986). Also, Petty, Cacioppo, and Schumann (1983) proposed that information quality has a strong influence on attitude change only when receivers have the high motivation or high ability to evaluate information; otherwise, whether and the extent that receivers have attitudinal shift is strongly influenced by peripheral persuasive cues such as information sources. Drawing on ELM theory, previous studies often considered message/information quality (the quality of arguments) taking the central route and information source characteristics (e.g., source credibility) taking the peripheral route to influence consumers' attitudes and behaviours (Le, Robinson, \& Dobele, 2020; Mahapatra \& Mishra, 2017). There is also research examining the impact of both source and message (Cheung \& Thadani, 2012; Mahapatra \& Mishra, 2017), as the two drivers of communication effectiveness in accordance with Hovland (1948)'s social communication theory.

The current study also uses ELM theory as the theoretical foundation to devise hypotheses and research models to address the research objectives. Specifically, the study examines the relationship between the information source characteristics (namely, online opinion leadership and parasocial interaction) and the message (message quality) in influencing behavioural intentions in the online social platforms.

\subsection{Online opinion leadership}

In the Internet environment (including social media), due to the characteristics of shortlived attention to and disproportionate popularity of the information (Susarla et al., 2016), the role of opinion leaders (information source) is very important, especially with a huge amount of information available on the Internet, it is challenging for consumers to be able to process all information. Several studies into information sources often incorporated opinion leadership - a personal source characteristic (Casaló et al., 2020; Le et al., 2020). Opinion leadership is defined as the extent to which an individual is perceived as a role model to others and the extent to which the information provided by that person is considered to be interesting and to be his or her persuasiveness (Casaló et al., 2020). Opinion leaders are those who have real expertise and experience with products or services, are searched for advice, or are able to disseminate information about products or services to others (Stokburger-Sauer \& Hoyer, 2009).

Thus, it can be argued in this research that the concept of opinion leadership can be extended to the online environment as online opinion leadership as the perceptions of a social platform-mediated individual as opinion leader that his or her information is seen interesting and has persuasive power. On social platforms, the concept of online opinion leaders can refer to either individual who has a broad knowledge or experience of a particular topic (expertise) or 
have many connections with others on social platforms; these individuals can disseminate information about products or services to others in the online environment (Goldenberg, Lehmann, Shidlovski, \& Barak, 2006). Individuals are perceived by social network sites' "friends" as the online opinion leaders can exert a certain influence on those "social friends" (Iyengar, Van den Bulte, \& Valente, 2010). Indeed, some research examined opinion leadership impacting behavioural intentions, independently of the message factor (Casaló et al., 2020).

\subsection{Parasocial interaction}

Parasocial interaction emerged from communication theory to explain the development of the relationship between personas on the mass media and receivers (Horton \& Wohl, 1956). Labrecque (2014) defined parasocial interaction as the illusionary experience in which the consumer interacts with personas (mediated representations of celebrities or characters) as if they engage directly in a two-way relationship with that celebrity or character. This is a persuasive cue of information sources (Sokolova \& Kefi, 2020). In the context of the Internet and social media, the relationship between online opinion leaders and followers can sometimes be two-way because users can add comments or discuss content or receive feedback from mediated representatives (website/blog administrator) (Labrecque, 2014). However, the real opinion leader cannot respond to all requests or participate in real discussions with followers due to a large number of followers; hence the relationship between online influencers and followers is indeed parasocial interactions (Sokolova \& Kefi, 2020). In this way, social platform users can establish relationships with online opinion leaders (bloggers/vloggers) by following or subscribing to their social channels/accounts and following the content that online influencers share. Thus, unlike Le et al. (2020)'s research, including source intimacy that could be more of reciprocal relationship, this study considers parasocial interaction instead as the interpersonal source characteristic regarding online opinion leaders.

\subsection{Message quality}

Communication research has also paid considerable attention to the type of information about products or services that are informally spread between people and termed as Word-OfMouth (WOM) (Anderson, 1998). The Internet and social media have led to a new form of WOM - electronic WOM (EWOM), which referred to information about products or services that is shared by online users to a large number of other online users (Hennig-Thurau, Gwinner, Walsh, \& Gremler, 2004) and is conceptually similar to UGC or CGC terms often used in influencer marketing practice. Message quality is defined as the compelling strength of the arguments embedded in the content of the information (Bhattacherjee \& Sanford, 2006)

\subsection{Behavioural intentions}

Prior research has examined the consequences of opinion leadership (Casaló et al., 2020) or final consequences of the causal path within the ELM (Le et al., 2020) that include behavioural intentions such as the intention to follow the advice of the opinion leader or the intention to recommend the message source. In the context of product reviews on social platforms, the current research investigated two behavioural intentions that are impacted by micro-influencership: The intention to follow the advice of the online opinion leader and the intention to recommend the social platform account/channel of the online opinion leader to others. The former captures the outcome favouring the firm and product embedded in the review, and the latter concerns the result in favour of the micro-influencer themselves. Intent to follow the advice is defined as the degree to which an individual thinks and follows the advice or reviews of online opinion leaders; and intention to recommend is the extent to which an 
individual is willing to refer (the social platform account/channel of) an online opinion leader to others with the same need or interest (Casaló et al., 2020).

\subsection{Development of hypothesis and research model}

Some prior EWOM research examined only the direct effects of both source and message factors on behavioural intentions (Cheung \& Thadani, 2012) or only source characteristics (Casaló et al., 2020; Sokolova \& Kefi, 2020). Those studies did not consider a basic tenet of the ELM model regarding the causal relationship of two routes of information processing. When the motivation or ability to process information is low, the receiver follows a peripheral route to process cues but gradually develops the ability to process the merits of information as in the central route (Petty \& Cacioppo, 1986). When consumers start to search for product reviews from online opinion leaders or to connect (subscribe/follow) to online opinion leaders' channels/accounts, consumers may not be able to process tons of information (posts or reviews by online opinion leaders, comments and replies by them and other followers, etc.). Therefore, consumers may first form perceptions of source cues, i.e., characteristics of the online opinion leader, then gradually, with acquired knowledge and interactive experience with the source they develop the ability and motivation to process the information offered by the online opinion leader (Petty \& Cacioppo, 1986).

Le et al. (2020)'s research has shown both characteristics of the source - personal characteristics and the interpersonal characteristics, have significant effects on the consumer perceptions of the message quality. In a similar vein, in the online environment, online opinion leadership and parasocial interaction, which are two persuasive cues of the information source, can be argued to relate to the perceived quality of the message because the appreciation of the source can lead to thorough processing of information and positive message evaluation (Petty \& Cacioppo, 1986). The online opinion leader can also, at times through their mediated representations interact with other users, thereby making others feel more attached to the source and trust the source's posts or reviews (Casaló et al., 2020). Thus, it can be hypothesised:

\section{H1: Online opinion leadership has a positive influence on message quality}

\section{H2: Parasocial interaction has a positive influence on message quality}

According to the ELM theory, the quality of the message (information or arguments) is a concept that is mostly processed in the central route, leading to the change in attitudinal evaluations and, finally consumer behaviours (Petty \& Cacioppo, 1986). Indeed, WOM and EWOM research have demonstrated information characteristics such as information/message quality can influence intentions or actual behaviours (Cheung \& Thadani, 2012; Sweeney, Geoffrey, \& Mazzarol, 2012). In the current study, behavioural intentions include both the intention relating to what is embedded in the message spread by the one opinion leader (intention to follow advice) and intention relating to the online opinion leader themselves for their having good taste regarding specific buying circumstances. If UGC/CGC is assessed positively, consumers will be more likely to have behavioural intentions relating to products or services imbedded in the message that online opinion leaders create and share. Thus, it can be hypothesised that:

H3: The message quality has a positive influence on the intention to follow the advice of the online opinion leader

H4: The message quality has a positive influence on the intention to recommend the social platform account/channel of the online opinion leader to others 
Figure 1 presents a visual representation of the hypothesised relationships discussed above

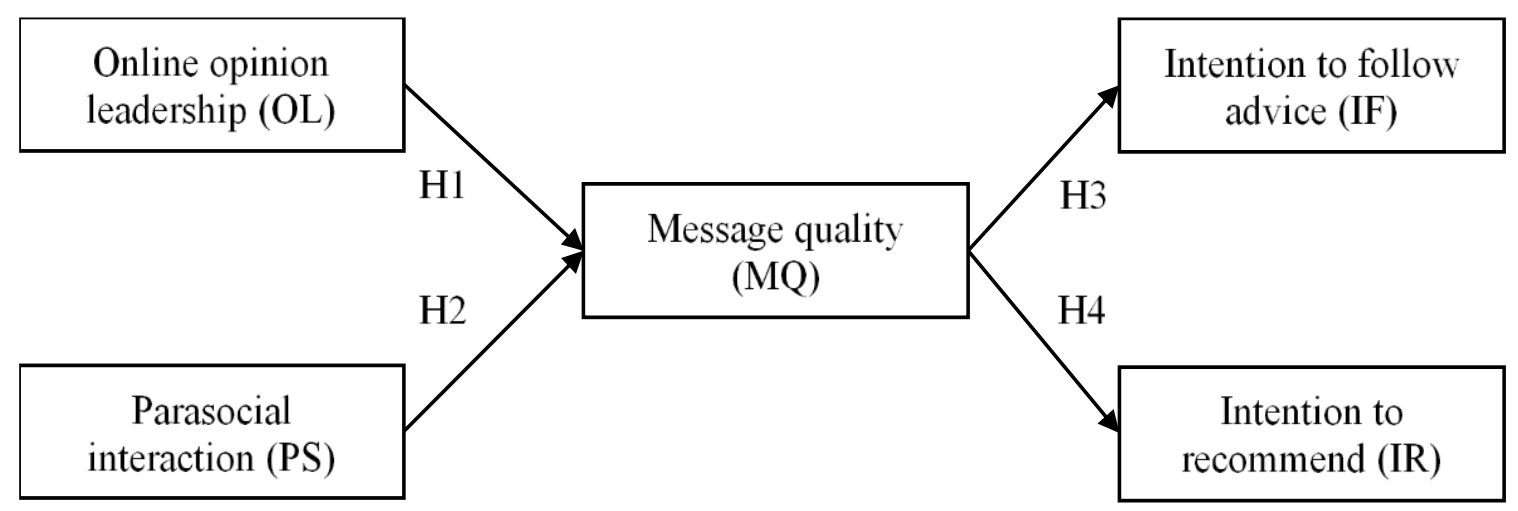

Figure 1. The proposed research model

\section{Methods}

The study adopted scales with good psychometric properties from previous studies to measure the concepts in the research model. Specifically, the scale of online opinion leadership (06 items) is adopted from (Casaló et al., 2020); parasocial interaction (06 items) from Labrecque (2014); message quality (05 items) from Le et al. (2020); intention to recommend (03 items) from Al-Ansi, Olya, and Han (2019); and intention to follow advice (04 items) from Casaló et al. (2020). Respondents will rate the degree of agreement of the statements (observed variable) using the 5-point Likert scale.

The questionnaire begins with screening questions to ensure that the criteria are met for selecting the survey respondents, who are consumers who view reviews about mobile phone products on social networking sites/online forums in the past 06 months in making a purchase or in planning to purchase. The scales are translated from English to Vietnamese and backtranslated, then the original version and the back-translated version are compared, and adjustments are made to ensure the scale content equivalence. After being designed, the survey questionnaire was pilot-tested with 02 experts and 10 consumers to ensure that the questionnaire content is easy to understand, unbiased, and free of grammatical and format errors.

Data was collected using the convenience sampling method by sending survey questionnaires to consumers who have previously purchased or planned to buy a mobile phone and viewed reviews about mobile phones before buying or to plan for the purchase. Given the high penetration of mobile devices in Vietnam, this sampling method deems appropriate to reach the above-described target population for this study. The mobile phone product was chosen because it was a high-involvement product, and information search is often conducted before making a purchase. The questionnaire is developed on the Google Form, and the link is emailed or posted to online social platforms such as Facebook or Zalo and online forum in August 2020. The respondents first indicated the social accounts (the micro-influencers) they have followed and watched, then rated the scale items related to their mentioned social accounts.

\section{Results and discussions}

\subsection{Sample characteristics}

There were 453 returned responses. After 82 responses from those who did not view product reviews about mobile phones on social platforms were excluded, data of 371 responses were usable for analysis using PLS-SEM. The demographic information of the sample is shown in Table 1 below. 


\section{Table 1}

Sample descriptive statistics

\begin{tabular}{|c|c|c|}
\hline Demographic variables & Frequency $(n=371)$ & Percentages $(\%)$ \\
\hline \multicolumn{3}{|l|}{ Gender } \\
\hline Male & 149 & $40.2 \%$ \\
\hline Female & 222 & $59.8 \%$ \\
\hline \multicolumn{3}{|l|}{ Age } \\
\hline $18-25$ & 108 & $29.1 \%$ \\
\hline $26-35$ & 186 & $50.1 \%$ \\
\hline $36-45$ & 61 & $16.4 \%$ \\
\hline Above 45 & & $4.3 \%$ \\
\hline \multicolumn{3}{|l|}{ Education } \\
\hline Up to high school & 61 & $16.4 \%$ \\
\hline University & 266 & $71.7 \%$ \\
\hline Postgraduate & 44 & $11.9 \%$ \\
\hline \multicolumn{3}{|l|}{ Occupation } \\
\hline Employee & 200 & $53.9 \%$ \\
\hline Student & 65 & $17.5 \%$ \\
\hline Manager/ director & 59 & $15.9 \%$ \\
\hline Self-employed & 42 & $11.3 \%$ \\
\hline Other & 5 & $1.3 \%$ \\
\hline \multicolumn{3}{|l|}{ Income } \\
\hline Below 12 million VND & 219 & $59.0 \%$ \\
\hline 12 - just less than 20 million VND & 99 & $26.7 \%$ \\
\hline 20 - just less than 30 million VND & 32 & $8.6 \%$ \\
\hline Above 30 million VND & 21 & $5.7 \%$ \\
\hline
\end{tabular}

Source: The researcher's data analysis

\subsection{Scale assessment}

Since the scales were adopted from previous studies, it is not necessary to evaluate the scales using the exploratory factor analysis method because the theoretical structures of the latent variables have been determined, and it may be inappropriate to make subjective decisions such as the number of factors to be extracted or discovered (Hair, Black, Babin, \& Anderson, 2010). As the current study using SmartPLS 3.2.7, the SmartPLS model includes a measurement model and structure model (Nguyen \& Vu, 2020). After estimating the SmartPLS model, the study first examined the item reliability (outer loadings), the convergent validity, and the discriminant validity of the scales. Both Cronbach's alpha and Combined Reliability (CR) coefficients were 
used to evaluate internal consistency with threshold $>0.7$, and a few observed variables may have loadings just $>0.5$ to be considered acceptable; and convergent validity is achieved when the Average Variance Extracted (AVE) is greater than 0.5 (Hair, Hult, Ringle, \& Sarstedt, 2016). The results in Table 2 show that most of the scales have Cronbach's Alpha, CR, and AVE values above the respective required thresholds, demonstrating the reliability and convergent validity of the scales measuring the concepts.

\section{Table 2}

The reliability and convergent validity

\begin{tabular}{lccccc}
\hline \multicolumn{1}{c}{ Concepts } & & Factor loadings & $\begin{array}{c}\text { Cronbach's } \\
\text { Alpha }\end{array}$ & CR & AVE \\
\hline Intention to follow & IF & {$[0.812-0.877]$} & 0.864 & 0.908 & 0.711 \\
Intention to recommend & IR & {$[0.844-0.884]$} & 0.835 & 0.901 & 0.752 \\
Message quality & MQ & {$[0.749-0.865]$} & 0.874 & 0.909 & 0.667 \\
Online opinion leadership & OL & {$[0.676-0.754]$} & 0.814 & 0.865 & 0.517 \\
Parasocial interaction & PS & {$[0.690-0.827]$} & 0.851 & 0.889 & 0.573 \\
\hline
\end{tabular}

Source: The researcher's data analysis

Hair et al. (2016) proposed that the discriminant validity is assessed using the criteria of Heterotrait-Monotrait (HTMT) values of less than 0.9. Results in Table 3 shows that HTMT values of concept pairs are less than 0.9 , the scales of the concepts achieve discriminant validity.

Table 3

Heterotrait-Monotrait Ratio (HTMT)

\begin{tabular}{lccccc}
\hline & & $\begin{array}{c}\text { Intention to } \\
\text { follow }\end{array}$ & $\begin{array}{c}\text { Intention to } \\
\text { recommend }\end{array}$ & $\begin{array}{c}\text { Message } \\
\text { quality }\end{array}$ & $\begin{array}{c}\text { Online } \\
\text { opinion } \\
\text { leadership }\end{array}$ \\
\hline Intention to recommend & IR & 0.883 & IR & MQ & OL \\
Message quality & MQ & 0.773 & 0.791 & & \\
Online opinion leadership & OL & 0.690 & 0.685 & 0.686 & \\
Parasocial interaction & PS & 0.830 & 0.846 & 0.740 & 0.722 \\
\hline
\end{tabular}

Source: The researcher's data analysis

\subsection{Structural model and hypothesis testing}

The result of the multi-collinearity test from the SmartPLS output shows that the maximum VIF value of latent variables is 1.566; thereby, multi-collinearity is not an issue in this research. The coefficients of determination $\left(\mathrm{R}^{2}\right)$ of the Intention to Follow advice (IF) and the Intention to Recommend (IR) are 0.455 and 0.459 , respectively, showing that with the research data, the model explains $45.5 \%$ and $45.9 \%$ respectively of the variation of Intention to Follow (IF) and Intention to Recommend (IR). In addition, the $\mathrm{R}^{2}$ value of Message Quality (MQ) is 0.477 , indicating that $47.7 \%$ variation of Message Quality (MQ) is explained by two concepts of 
online Opinion Leadership (OL) and Parasocial Interaction (PS). Besides $\mathrm{R}^{2}$, another means of assessing predictive accuracy that is $\mathrm{Q}^{2}$ was also calculated using the SmartPLS blindfolding procedure with an omission distance of six. Results also show that $\mathrm{Q}^{2}$ of Intention to Follow (IF), Intention to Recommend (IR), and Message Quality (MQ) are 0.297, 0.319, and 0.287, respectively; all are larger than zero, indicating that these endogenous variables have predictive relevance with their respective predecessors (Hair, Jeffrey, Sarstedt, \& Christian, 2019).

The results of testing the structural model by the bootstrapping method (Figure 1) show that online Opinion Leadership (OL) has a significant, positive impact on the Message Quality (MQ) $(\beta=0.315 ; p<0.001)$ and Parasocial Interaction (PS) also has a significant, positive impact on the Message Quality (MQ) $(\beta=0.455 ; \mathrm{p}<0.001)$. Therefore, hypotheses H1 and H2 are supported. The results also show that the Message Quality (MQ) has a significant, positive impact on the Intention to Follow (IF) $(\beta=0.667 ; p<0.001)$ as well as on the intention to recommend (IR) $(\beta=0.682 ; \mathrm{p}<0.001)$. Therefore, hypothesis $\mathrm{H} 3$ and $\mathrm{H} 4$ are supported.

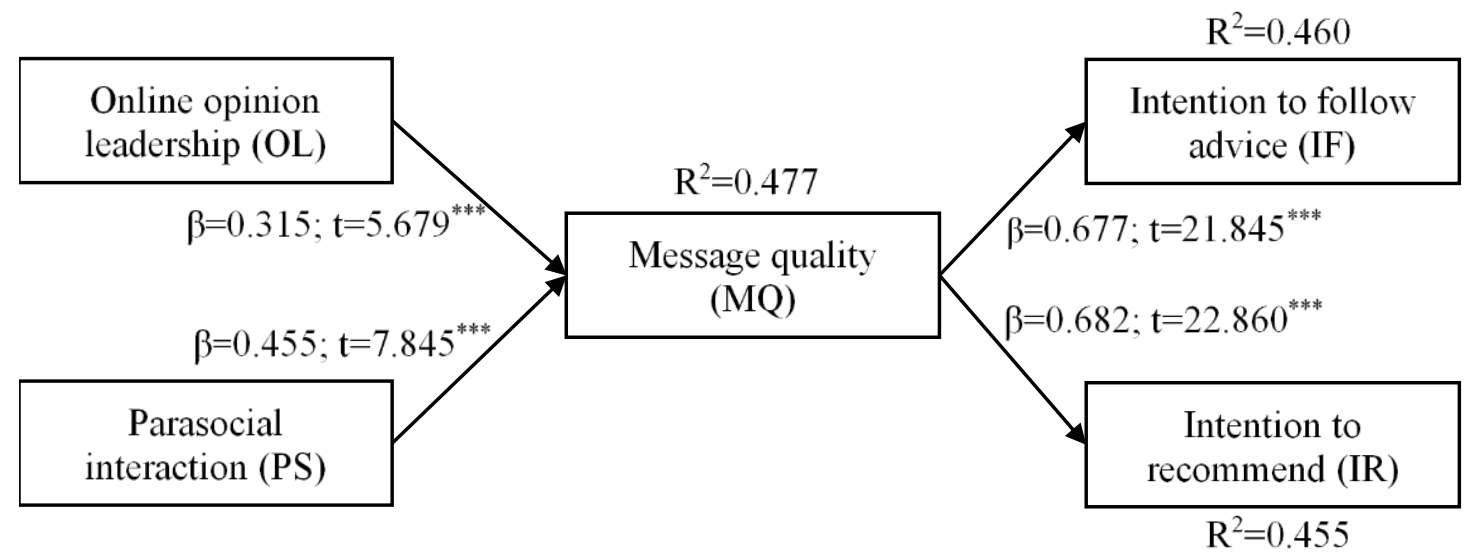

Figure 2. Testing of structural equation model (using bootstrapping)

Note: *** Statistically significant at $\mathrm{p}<0.001$

With all hypotheses having been supported based on estimation using the bootstrapping method, according to Preacher and Hayes (2008), it is possible to conclude the mediating role of message quality in the relationship between the source characteristics and consumers' behavioural intentions. Table 4 presents the results of the indirect effects of the SmartPLS-based structural equation modeling by bootstrapping. The results provided further evidence of the mediating role of message quality (all p-values below 0.05), with total indirect effects of parasocial interaction on both behavioural intentions via message quality being larger than those of online opinion leadership.

\section{Table 4}

Indirect effects

\begin{tabular}{lcccc}
\hline & Sample Mean & Standard Deviation & T Statistics & P Values \\
\hline OL -> MQ -> IF & 0.215 & 0.040 & 5.260 & 0.000 \\
PS -> MQ -> IF & 0.309 & 0.047 & 6.516 & 0.000 \\
OL -> MQ -> IR & 0.216 & 0.041 & 5.175 & 0.000 \\
PS -> MQ -> IR & 0.311 & 0.047 & 6.641 & 0.000 \\
\hline
\end{tabular}

Source: The researcher's data analysis 


\subsection{Discussions}

Research results show that online opinion leadership and parasocial interaction have a positive effect on message quality. In turn, message quality positively affects both the intention to follow advice (i.e., to respond to the product information embedded in the message) spread by the online opinion leader and the intention relating to the online opinion leader (to recommend to others). More generally, in this research, the source and message characteristics both play a role in driving consumers' behavioural intentions. This overall finding is consistent with the studies such as Cheung and Thadani (2012) examining both source and message influence on customer behavioural intentions; as well as is consistent with studies into the influence of source characteristics such as online opinion leadership (Casaló et al., 2020) or parasocial interaction (Sokolova \& Kefi, 2020) on behavioural intentions.

Unlike many previous studies, this study examines the causal relationships between source and message characteristics in line with the causality between two routes of persuasion stipulated in the ELM theory (Petty \& Cacioppo, 1986). The findings in this study are broadly consistent with Le et al. (2020) in that perceptions of source characteristics lead to the perceptions of message quality and subsequently to the consumer's behavioural intention. However, Le et al. (2020) considered interpersonal relationship characteristic of information source being represented by source intimacy - a close relationship or bond with the source as if in a reciprocal relationship. In the context of the Internet and social media, it is not always possible that the online opinion leaders interact or have real relationships with their followers, so this study considers the interpersonal relationship characteristic of the source to be represented by perceptions of parasocial relationship in which the source may not know the followers but can still have an influence on their behaviour (Labrecque, 2014).

In this study, message quality acts as a mediating variable in the relationship between source characteristics and customer behavioural intention. According to Kenny (2008), it is not necessary to assess whether there is partial or full intermediation. Although some studies found that source characteristics can have a direct influence on behavioural intentions (Casaló et al., 2020; Cheung \& Thadani, 2012; Sokolova \& Kefi, 2020); this study focuses on the causal mechanism in line with ELM theory and the parsimony requirement of theory.

\section{Conclusion}

This research contributes to the advances in information processing theories related to consumers who process persuasive cues and information about the products or services exposed to them through the online environment. The result on the mediating role of the message quality also supports the causality of the information processing routes in accordance with the ELM model when consumers are exposed to a huge amount of information on the online platforms and are unable to process the information thoroughly. Moreover, the research also contributes evidence on information procession theories and the application of ELM theory in the emerging market context, which is an important marketing context where current research is scant.

This research also provides implications for managers to build digital marketing strategies incorporating influencer marketing and EWOM marketing. Although UGCs are noncommercial and influencers may not be for monetary benefits, marketers can still influence influencers on social platforms and their generated and disseminated content (arguments). Specifically, marketers need to detect influencers on online social platforms and target them with appropriate communication strategies so that this audience will be the creator and distributor of UGCs affecting final consumers. In addition, the finding of the mediating role of message 
quality shows that once consumers move from the peripheral cue processing route to the central information merit processing route, the marketers must also monitor and assess the consumer's perceptions of the message quality through the online opinion leaders. The result also shows that a micro-influencer when conveying a quality message about the business's products or services benefits not only the business but also themselves.

Like any other study, this study has some limitations that may be considered for venues for future research. This study was a cross-sectional survey, so in the future, it is possible to combine other methods such as longitudinal studies to increase the generalisability of the results. Questionnaires were sent to potential respondents in the Ho Chi Minh City area, so to generalise and confirm the results found in this study, future studies may need to be expanded to a sample in the larger geographic area such as other regions in Vietnam and other countries. In addition, research may also need to be considered with other product and service categories. Finally, in this study, the message factor was operationalised as message quality, and future research may consider other message characteristics that may also influence consumer behavioural intentions.

\section{References}

Abidin, C. (2016). Visibility labour: Engaging with Influencers' fashion brands and \#OOTD advertorial campaigns on Instagram. Media International Australia, 161(1), 86-100.

Al-Ansi, A., Olya, H. G. T., \& Han, H. (2019). Effect of general risk on trust, satisfaction, and recommendation intention for halal food. International Journal of Hospitality Management, 83, 210-219.

Anderson, E. W. (1998). Customer satisfaction and word of mouth. Journal of Service Research, $1(1), 5-17$.

Bhattacherjee, A., \& Sanford, C. (2006). Influence processes for information technology acceptance: An Elaboration Likelihood Model. MIS Quarterly, 30(4), 805-825.

Bijen, Y. J. (2017). \#AD: The effects of an influencer, comments and product combination on brand image (Master's thesis). University of Twente, Enschede, Netherlands.

Casaló, L. V., Flavián, C., \& Ibáñez-Sánchez, S. (2020). Influencers on Instagram: Antecedents and consequences of opinion leadership. Journal of Business Research, 117, 510-519.

Chatterjee, P. (2011). Drivers of new product recommending and referral behaviour on social network sites. International Journal of Advertising, 30(1), 77-101.

Cheung, C. M. K., \& Thadani, D. R. (2012). The impact of electronic word-of-mouth communication: A literature analysis and integrative model. Decision Support Systems, 54(1), 461-470.

De Veirman, M., Cauberghe, V., \& Hudders, L. (2017). Marketing through Instagram influencers: The impact of number of followers and product divergence on brand attitude. International Journal of Advertising, 36(5), 798-828.

Depouilly, X. (2019). Vietnam in the digital era: Evolution, impacts and social considerations. Retrieved November 1, 2020, from https://indochina-research.com/wpcontent/uploads/1912-Digital-Vietnam-2019-by-Indochina-Research.pdf

Djafarova, E., \& Trofimenko, O. (2019). 'Instafamous' - Credibility and self-presentation of microcelebrities on social media. Information, Communication \& Society, 22(10), 1432-1446. 
Gentina, E., Butori, R., \& Heath, T. B. (2014). Unique but integrated: The role of individuation and assimilation processes in teen opinion leadership. Journal of Business Research, 67(2), 83-91.

Goldenberg, J., Lehmann, D. R., Shidlovski, D., \& Barak, M. M. (2006). The role of expert versus social opinion leaders in new product adoption. Marketing Science Institute Reports (Working Paper Series), 6(4), 67-84.

Hair, J. F., Black, W. C., Babin, B. J., \& Anderson, R. E. (2010). Multivariate data analysis (7th ed.). Upper Saddle River, NJ: Prentice Hall.

Hair, J. F., Hult, G. T. M., Ringle, C., \& Sarstedt, M. (2016). A primer on Partial Least Squares Structural Equation Modeling (PLS-SEM). Thousand Oaks, CA: Sage Publications.

Hair, J. F., Jeffrey, J. R., Sarstedt, M., \& Christian, M. R. (2019). When to use and how to report the results of PLS-SEM. European Business Review, 31(1), 2-24.

Hennig-Thurau, T., Gwinner, K. P., Walsh, G., \& Gremler, D. D. (2004). Electronic word-ofmouth via consumer-opinion platforms: What motivates consumers to articulate themselves on the Internet? Journal of Interactive Marketing, 18(1), 38-52.

Horton, D., \& Wohl, R. R. (1956). Mass communication and para-social interaction. Psychiatry, 19(3), 215-229.

Hovland, C. I. (1948). Social communication. Proceedings of the American Philosophical Society, 92(5), 371-375.

Ilicic, J., \& Webster, C. M. (2014). Investigating consumer-brand relational authenticity. Journal of Brand Management, 21(4), 342-363.

Iyengar, R., Van den Bulte, C., \& Valente, T. W. (2010). Opinion leadership and social contagion in new product diffusion. Marketing Science, 30(2), 195-212.

Kenny, D. A. (2008). Reflections on mediation. Organizational Research Methods, 11(2), 353-358.

Labrecque, L. I. (2014). Fostering consumer-brand relationships in social media environments: The role of parasocial interaction. Journal of Interactive Marketing, 28(2), 134-148.

Le, T. D., Robinson, L. J., \& Dobele, A. R. (2020). Word-of-mouth information processing routes: The mediating role of message and source characteristics. Journal of Consumer Behaviour, 19(2), 171-181.

Li, Y.-M., Lee, Y.-L., \& Lien, N.-J. (2012). Online social advertising via influential endorsers. International Journal of Electronic Commerce, 16(3), 119-154.

Mahapatra, S., \& Mishra, A. (2017). Acceptance and forwarding of electronic word of mouth. Marketing Intelligence \& Planning, 35(5), 594-610.

Min, J. H. J., Chang, H. J. J., Jai, T.-M. C., \& Ziegler, M. (2019). The effects of celebrity-brand congruence and publicity on consumer attitudes and buying behavior. Fashion and Textiles, 6(1), 1-19.

Nguyen, H. M., \& Vu, T. H. (2020). Phân tích dĩ liệu áp dụng mô hình PLS - SEM [Data analysis using PLS - SEM model]. Ho Chi Minh, Vietnam: NXB Kinh Tế Thành Phố Hồ Chí Minh.

Park, C. S., \& Kaye, B. K. (2017). The tweet goes on: Interconnection of Twitter opinion 
leadership, network size, and civic engagement. Computers in Human Behavior, 69, 174-180.

Petty, R. E., \& Cacioppo, J. T. (1986). Communication and persuasion: Central and peripheral routes to attitude change. New York, NY: Springer-Verlag.

Petty, R. E., Cacioppo, J. T., \& Schumann, D. (1983). Central and peripheral routes to advertising effectiveness: The moderating role of involvement. Journal of Consumer Research, 10(2), 135-146.

Preacher, K., \& Hayes, A. (2008). Asymptotic and resampling strategies for assessing and comparing indirect effects in multiple mediator models. Behavior Research Methods, 40(3), 879-891.

Sheth, J. N. (2011). Impact of emerging markets on marketing: Rethinking existing perspectives and practices. Journal of Marketing, 75(4), 166-182.

Sokolova, K., \& Kefi, H. (2020). Instagram and YouTube bloggers promote it, why should I buy? How credibility and parasocial interaction influence purchase intentions. Journal of Retailing and Consumer Services, 53, Article 101962.

Stokburger-Sauer, N. E., \& Hoyer, W. D. (2009). Consumer advisors revisited: What drives those with market mavenism and opinion leadership tendencies and why? Journal of Consumer Behaviour, 8(2/3), 100-115.

Susarla, A., Oh, J.-H., \& Tan, Y. (2016). Influentials, imitables, or susceptibles? Virality and Word-of-Mouth conversations in online social networks. Journal of Management Information Systems, 33(1), 139-170.

Sweeney, J. C., Geoffrey, N. S., \& Mazzarol, T. (2012). Word of mouth: Measuring the power of individual messages. European Journal of Marketing, 46(1/2), 237-257.

Trusov, M., Bucklin, R. E., \& Pauwels, K. (2009). Effects of Word-of-Mouth versus traditional marketing: Findings from an Internet social networking site. Journal of Marketing, 73(5), 90-102.

We Are Social, \& Hootsuite. (2019). Digital 2019 - Vietnam. Retrieved November 1, 2020, from https://datareportal.com/reports/digital-2019-vietnam 
Creative Commons Attribution-NonCommercial 4.0 International License. 